\title{
WYKORZYSTANIE METODY DEA DO ANALIZY EFEKTYWNOŚCI ZARZĄDZANIA RYZYKIEM W WYBRANYCH BANKACH
}

\begin{abstract}
Problem oceny i pomiaru efektywności zajmuje wiele miejsca w literaturze ekonomicznej. W ujęciu ekonomicznym efektywność wiąże się z relacjami pomiędzy uzyskanymi efektami a nakładami potrzebnymi do ich uzyskania. Im wyższy jest stosunek wypracowanych efektów do poniesionych nakładów, tym efektywność danego systemu będzie uznawana z wyższą. Stąd widać, że bardziej efektywne systemy potrzebują mniejszych nakładów do uzyskania danego efektu lub przy tych samych nakładach uzyskują wyższe efekty. W odniesieniu do systemów zarządzania ryzykiem finansowym w banku efektywność w ujęciu ekonomicznym będzie mogła zostać mierzona poprzez zbadanie relacji pomiędzy zyskownością banku a ryzykiem związanym z jego działalnością. W artykule zaprezentowano, w jaki sposób można ocenić efektywność zarządzania ryzykiem w banku, wykorzystując metodę DEA (Data Envelopment Analysis). Aby takiej oceny dokonać, należało odpowiednio zdefiniować nakłady i efekty funkcjonowania systemu zarządzania ryzykiem. Przyjęto, że efektem funkcjonowania systemu jest wynik finansowy osiagany przez bank. Poprzez system zarządzania ryzykiem, który jest wkomponowany $\mathrm{w}$ cały proces zarządzania aktywami i pasywami banku, można sterować wysokością podejmowanego ryzyka oraz wpływać na poziom wyników osiaganych przez bank. Efektywność systemu będzie się wyrażała poprzez osiaganie danego wyniku przy jak najmniejszym poziomie podejmowanego ryzyka. Analizie poddano ryzyko podejmowane przez banki w relacji do osiaganego przez nie wyniku finansowego. Badaniem objęto banki notowane na Giełdzie Papierów Wartościowych w Warszawie, do analizy wykorzystano dane finansowe banków za lata 2012-2013.
\end{abstract}

Słowa kluczowe: zarządzanie ryzykiem, efektywność, metoda DEA

\section{WPROWADZENIE}

Zgodnie z teorią organizacji efektywność określa relację pomiędzy nakładami a efektami uzyskanymi dzięki ich wykorzystaniu. Efektywność może być rozumiana także nieco inaczej. Zakładając, że w każdej organizacji istnieją cele, które mają zostać zrealizowane, efektywność można definiować jako stopień, w jakim organizacja realizuje swoje cele. Często wymiennie zamiast pojęcia efektywności stosuje się zapożyczone z prakseologii pojęcie skuteczności ${ }^{3}$. Tak więc efektywność systemu zarządzania ryzykiem finansowym w banku rozpatrywana według teorii organizacji oznacza stopień realizacji

\footnotetext{
${ }^{1}$ Dr Agata Gemzik-Salwach, Katedra Finansów, Wyższa Szkoła Informatyki i Zarządzania w Rzeszowie

2 Dr inż. Paweł Perz, Zakład Finansów i Bankowości, Wydział Zarządzania, Politechnika Rzeszowska, ul. Powstańców Warszawy 8, 35-959 Rzeszów, autor korespondencyjny, e-mail: pperz@prz.edu.pl

3 J. Kudła, Struktury organizacyjne banków komercyjnych, Twigger, Warszawa 2001, s. 179.
} 
celów, jakie zostały postawione w banku wobec systemu zarządzania ryzykiem. Mimo wydawałoby się - jasnej i prostej definicji efektywności, jej ocena nie jest łatwym zadaniem. Wynika to chociażby $\mathrm{z}$ istnienia wielorakich celów stawianych przed systemami zarządzania ryzykiem. Powstaje problem oceny efektywności w sytuacji zróżnicowanego stopnia realizacji celów - praktycznie system zawsze będzie bowiem w pełni realizował tylko część celów, pozostałe zostaną niezrealizowane bądź zrealizowane jedynie w części. W takim wypadku należałoby mówić o efektywności systemu w pewnych aspektach jego działalności i nieefektywności w innych. W pewnym stopniu skłaniałoby to do prób wartościowania celów i analizy skuteczności w realizacji celów najważniejszych, to z kolei powoduje powstanie nowych problemów związanych $\mathrm{z}$ procesem hierarchizacji celów. Innym problemem jest ocena stopnia realizacji poszczególnych celów. W organizacji istnieje bowiem wiele celów, których realizację trudno kwantyfikować. Te wszystkie powody sprawiają, że jednoznaczne przyporządkowanie danego systemu do grupy systemów efektywnych lub nieefektywnych jest niezwykle skomplikowane. Dodatkową trudność sprawia fakt, że oprócz stopnia realizacji celów, oceniając efektywność z punktu widzenia teorii organizacji, analizuje się i ocenia również nakłady, które pozwoliły na osiągnięcie tych celów. Tak więc ocena efektywności zgodnie z tą interpretacją w pierwszej kolejności dotyczy stopnia realizacji celów, w drugiej fazie zaś relację pomiędzy osiągniętymi celami a nakładami poniesionymi na ich zrealizowanie. System jest tym efektywniejszy, w im większym stopniu realizuje swoje cele i im mniejsze nakłady wykorzystuje do ich realizacji. Przyjęcie dwóch kryteriów potęguje jeszcze niejednoznaczności, dlatego że pojawiają się trudności w ocenie systemów, które nie w pełni zrealizowały cele i poniosły przy tym różne nakłady.

W niniejszym artykule autorzy zakładają, że najważniejszym celem systemu jest maksymalizacja zysku przy założeniu nieprzekroczenia limitu ryzyka ustalonego w banku. Ponieważ ryzyko i zysk ze sobą współzależne, a jednocześnie zewnętrzne warunki ryzyka są identyczne dla wszystkich banków działających na jednym rynku, główny cel systemu zarządzania ryzykiem może być realizowany poprzez maksymalizację relacji zysk-ryzyko. Na podstawie stopnia realizacji tego celu można dokonać względnej klasyfikacji efektywności systemów zarządzania ryzykiem, porównując wyniki osiągane przez poszczególne banki z ryzykiem, jakie podejmowały w celu jego osiagnięcia. Ważnym warunkiem, który pozwala na dokonywanie takiej oceny, jest funkcjonowanie banków w identycznych warunkach ryzyka wyznaczonych przez otoczenie rynkowe banków. Podstawowe parametry rynkowe, takie jak korelacja i zmienność cen poszczególnych instrumentów, stóp procentowych, kursów walut, są na danym rynku jednakowe. W takich warunkach jakość zarządzania ryzykiem jest kluczowym czynnikiem wpływającym na relację ryzyko-zysk. Ocena efektywności sytemu zarządzania ryzykiem opiera się na analizie ryzyka, jakie podejmował bank, aby osiągnąć dany poziom wyniku finansowego.

\section{METODY OCENY EFEKTYWNOŚCI}

Wśród licznych metod oceniających efektywność systemów można wyróżnić dwie podstawowe grupy: metody parametryczne i metody nieparametryczne. Metody parametryczne opierają się na analizie funkcji opisującej zależność pomiędzy nakładami i efektami wynikającymi z ich zastosowania. Do największych trudności, jakie są związane 
z zastosowaniem metod parametrycznych, można zaliczyć przede wszystkim konieczność znajomości funkcyjnej zależności pomiędzy nakładami a efektami. Dodatkowo, aby wyniki otrzymanej estymacji parametrów funkcji opisującej zależność pomiędzy nakładami a efektami były wystarczająco dokładne potrzebne jest wykorzystanie dużej liczby danych empirycznych. W wypadku badania polskiego sektora bankowego populacja składająca się ze wszystkich banków mogłaby się okazać zbyt małą próbą do uzyskania wystarczająco wiarygodnych wyników.

Drugą grupą metod, które mogą posłużyć do analizy efektywności, są metody nieparametryczne, które pozwalają na uniknięcie wielu trudności pojawiających się podczas wykorzystywania metod parametrycznych. Jedną z podstawowych zalet metod nieparametrycznych jest brak konieczności określania funkcyjnej zależności pomiędzy danymi opisującymi nakłady i efekty. Na obecnym etapie rozwoju polskiego sektora bankowego, w obliczu ograniczonej dostępności danych, metody nieparametryczne, a wśród nich metoda Data Envelopment Analysis (DEA), należy uznać za zdecydowanie bardziej przydatne dla celów analizy ${ }^{4}$.

Punktem wyjścia dla metody ${ }^{5}$ DEA jest definicja efektywności, która przyjmuje następującą postać:

$$
\text { EFEKTYWNOŚC }=\frac{E F E K T}{\text { NAKEAD }}
$$

Model DEA wykorzystuje tę zależność do opisu przypadku, kiedy analizowany system wykorzystuje nie pojedynczy nakład, a kilka nakładów i w ich efekcie uzyskuje kilka efektów. Wtedy efektywność takiego systemu może zostać opisana następującym wzorem:

$$
\text { EFEKTYWNOŚC }=\frac{\sum_{Y=1}^{F} \mu_{r} E_{F E R T_{T}}}{\sum_{i=1}^{M} V_{i} N A R E A D_{i}} \times 100 \%
$$

gdzie:

s - liczba efektów,

m - liczba nakładów,

$\mu \mathrm{r}$ - wagi określające ważność efektów,

vi - wagi określające ważność nakładów.

W metodzie DEA obiekty, które podlegają analizie, noszą nazwę jednostek decyzyjnych (DMU, Decision Making Units). Efektywność danej jednostki decyzyjnej jest mierzona względem innych. Na podstawie danych empirycznych opisujących nakłady i efekty dla danego systemu metoda konstruuje krzywą obrazującą zależność pomiędzy tymi wielkościami. Krzywa efektywności jest graficznym obrazem różnych możliwych do uzyskania efektów wynikających z użycia różnych kombinacji nakładów. Obiekty, które można uznać za efektywne mają współczynnik efektywności wynoszący $100 \%$ i leżą na krzywej efektywności. Wszystkie obiekty leżące poniżej krzywej mają współczynnik

\footnotetext{
${ }^{4}$ G. Rogowski, Metody analizy i oceny dziatalności banku na potrzeby zarzadzania strategicznego, Wydawnictwo Wyższej Szkoły Bankowej w Poznaniu, Poznań 1998, s. 129.

${ }^{5}$ Opisując metodę DEA, autorzy opierali się na pracach: G. Rogowski, op. cit., s. 129-152; A. Charnes, W.W. Cooper, A.Y. Lewin, L.M. Seiford, Data Envelopment Analysis: Theory, Methodology and Aplications, Kluwer Academic Publishers, Dordrecht 1995.
} 
efektywności należący do przedziału 0-100\% - im mniejsza wartość tego współczynnika, tym niższy stopień efektywności danego systemu. W metodzie DEA nie jest potrzebna wcześniejsza znajomość wag określających poziom ważności poszczególnych nakładów i efektów (współczynniki $\mu$ r, vi), dla danej jednostki decyzyjnej (systemu) wyznaczane są wagi, które maksymalizują jego efektywność.

$$
\max _{\mu, v} \frac{\sum_{r=1}^{s} \mu_{r} y_{r o}}{\sum_{i=1}^{m} v_{i} x_{i o}}
$$

z uwzględnieniem następujących ograniczeń:

$$
\begin{aligned}
& \frac{\sum_{r=1}^{s} \mu_{r} y_{r j}}{\sum_{i=1}^{m} v_{i} x_{i j}} \leq 1 \\
& \mu \mathrm{r}, v \mathrm{i} \geq 0 \\
& \text { dla } \mathrm{j}=0,1, \ldots, \mathrm{n} \text {, } \\
& \frac{\mu_{r}}{\sum_{i=1}^{m} v_{i} x_{i o}} \geq \mathcal{E} \\
& \text { dla } \mathrm{r}=0,1, \ldots, \mathrm{s}, \\
& \frac{v_{i}}{\sum_{i=1}^{m} v_{i} x_{i o}} \geq \mathcal{E} \\
& \text { dla } \mathrm{i}=0,1, \ldots, \mathrm{m} \text {. }
\end{aligned}
$$

Wykorzystując metodę transformacji Charnesa-Coopera, można nieliniową postać modelu DEA przedstawić w postaci zagadnienia programowania liniowego. Funkcja celu w takim modelu może zostać przedstawiona następująco:

$$
\max _{\mu, v} w_{o}=\sum_{r=1}^{s} \mu_{r} y_{r o}
$$

przy ograniczeniach:

$$
\begin{aligned}
& \sum_{i=1}^{n} v_{i} x_{i o}=1 \\
& \sum_{r=1}^{s} \mu_{r} y_{r j}-\sum_{i=1}^{m} v_{i} x_{i j} \leq 0 \\
& \mu_{r} \geq \mathcal{E},
\end{aligned}
$$


$v_{i} \geq \varepsilon$

Tak sformułowaną postać modelu można rozwiązywać, wykorzystując metody programowania linowego.

\section{OCENA EFEKTYWNOŚCI ZARZĄDZANIA RYZYKIEM W BANKACH}

Do badania efektywności systemu zarządzania ryzykiem w banku wykorzystano model DEA, w którym występują trzy nakłady i jeden efekt - schemat takiego modelu przedstawiono na rysunku 1

Rys. 1. Schemat modelu Data Envelopment Analysis (DEA) wykorzystany do badania efektywności

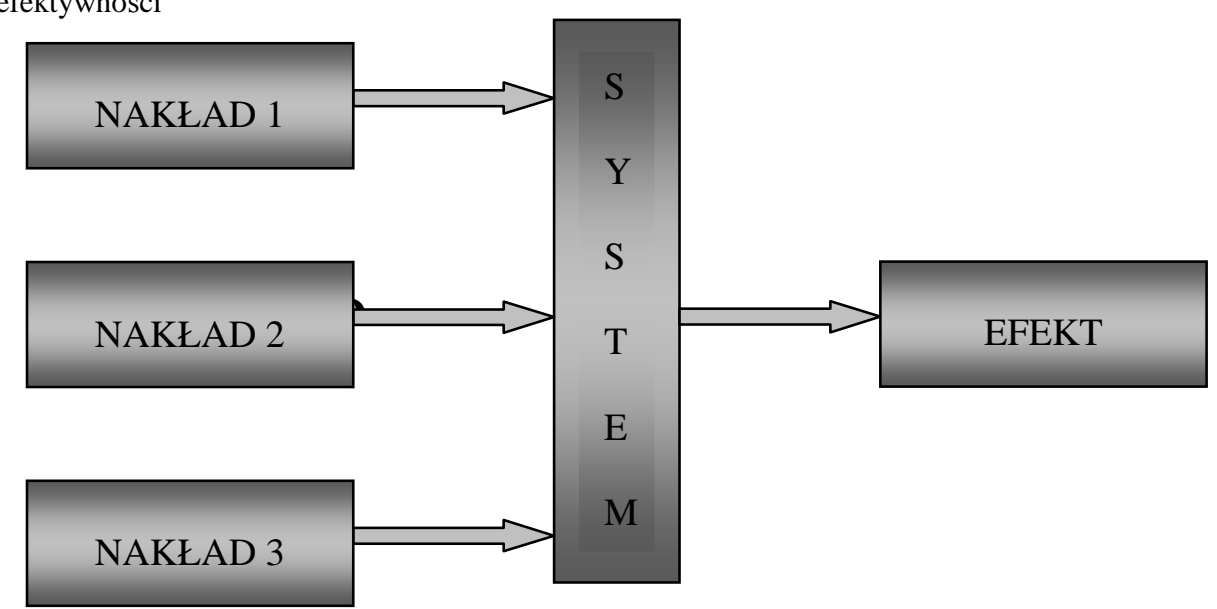

Źródło: opracowanie własne.

W niniejszej analizie autorzy badają zależności pomiędzy podejmowanym przez bank ryzykiem a finansowymi efektami działalności banku. Celem systemu zarządzania ryzykiem jest optymalizacja relacji pomiędzy podejmowanym przez bank ryzykiem i wynikami finansowymi, jakie dany podmiot osiaga. W zależności od założeń strategii banku realizacja tego celu może się odbywać poprzez minimalizację ryzyka podejmowanego dla osiągnięcia danego wyniku finansowego lub też maksymalizację wyniku finansowego osiąganego przy danym poziomie ryzyka. Wobec takich założeń dotyczących celu systemu zarządzania ryzykiem efektywność tego systemu można zbadać, obserwując relację pomiędzy osiaganymi przez bank wynikami finansowymi a podejmowanym przez bank ryzykiem. Poprzez system zarządzania ryzykiem, który jest wkomponowany w cały proces zarządzania aktywami i pasywami banku, można sterować wysokością podejmowanego ryzyka oraz wpływać na poziom wyników osiąganych przez 
bank. Efektywność systemu będzie się wyrażała poprzez osiaganie danego wyniku przy jak najmniejszym poziomie podejmowanego ryzyka ${ }^{6}$.

Do obliczeń wykorzystano dwa różne modele różniące się przyjętą do oceny kategorią wyniku finansowego. W pierwszym modelu do analizy zastosowano wynik na działalności bankowej. W drugim modelu posłużono się zyskiem brutto. Zarówno jedna, jak i druga kategoria wyniku finansowego, użyta w modelu jako odzwierciedlenie efektów funkcjonowania banku, ma zalety i wady. Wynik na działalności bankowej dobrze odzwierciedla istotę efektów funkcjonowania banku w sferze finansowej, nie jest przy tym zniekształcony przez wpływ innych czynników niezależnych od zarządzania ryzykiem (takich jak stopa opodatkowania czy koszty funkcjonowania banku). Jego wadą jest to, że nie bierze się pod uwagę rezerw tworzonych przez bank. W zysku brutto, który jest wykorzystywany w drugim modelu, uwzględnia się wpływ tworzonych przez bank komercyjny rezerw, jednak na jego wysokość wpływaja takie czynniki, jak koszty funkcjonowania banku.

Ryzyko w funkcjonowaniu systemu wyrażone jest poprzez zmienność poszczególnych kategorii wyniku na działalności bankowej osiaganego przez bank. Na bazie zmienności wyników finansowych, jakie bank osiagnął (wyniku z tytułu odsetek, wyniku na działalności finansowej oraz wyniku z pozycji wymiany), wyznaczono adekwatny do tej zmienności poziom kapitału ekonomicznego. Tak wyrażony kapitał ekonomiczny jest obiektywną i adekwatną miarą ryzyka, jakie bank podejmował w danym obszarze swojego funkcjonowania. Tak więc nakładami w modelu sa kapitały ekonomiczne niezbędne do pokrycia ryzyka $\mathrm{z}$ poszczególnych obszarów działalności banku (działalności odsetkowe, operacji finansowych i walutowych). Do zbadania stopnia efektywności poszczególnych systemów zarządzania ryzykiem wykorzystano jeden z wariantów metody DEA - model określany jako model $\mathrm{CCR}^{7}$. Jest to model zorientowany na nakłady. W modelu tym bada się, czy dany system mógł osiagnąć dany zestaw efektów, wykorzystując mniejsze nakłady. W modelu efektywnym współczynnik efektywności wynosi 100\% i oznacza to, że nie istnieje bardziej efektywna kombinacja nakładów umożliwiająca osiagnięcie danego efektu. W wypadku modelu zdefiniowanego wyżej współczynnik efektywności równy $100 \%$ będzie oznaczał, że nie było możliwe osiągnięcie danego wyniku finansowego przy użyciu mniejszego kapitału ekonomicznego, a ponieważ kapitał ekonomiczny odzwierciedla podejmowane przez bank ryzyko, będzie to oznaczało, iż nie można było uzyskać danego wyniku finansowego, ponosząc mniejsze ryzyko. Współczynnik efektywności mniejszy niż 100\% wskazuje na to, że dany system był nieefektywny - to znaczy możliwe było zastosowanie innej kombinacji kapitału ekonomicznego (co świadczy o podjęciu mniejszego ryzyka) do uzyskania danego wyniku finansowego.

Szczegółowy schemat funkcjonowania systemu zarządzania ryzykiem, sporządzony dla celów analizy efektywności metodą DEA, zaprezentowano na rysunku 2 . W systemie

\footnotetext{
${ }^{6}$ Efektywność zdefiniowano w taki sposób, ponieważ do badań efektywności wykorzystano model DEA zorientowany na nakłady. Zamiennie można byłoby również przyjąć, że efektywność będzie się wyrażała poprzez maksymalizacje wyników przy danym poziomie ryzyka.

${ }^{7}$ Nazwa tego wariantu metody DEA pochodzi od nazwisk autorów artykułu w którym po raz pierwszy ją: zob. A. Charnes, W. Cooper, E. Rhodes, Measuring the efficiency of decision-making units, European Journal of Operational Research 1978 vol. 2
} 
zarządzania ryzykiem wyodrębniono trzy podsystemy, których zadaniem jest zarządzanie trzema dużymi grupami ryzyka: ryzykiem kredytowym, rynkowym i operacyjnym. Podział na wymienione grupy jest zgodny z zaleceniami Bazylejskiego Komitetu ds. Nadzoru Bankowego. Poszczególne podsystemy zarządzania ryzykiem wzajemnie się przenikają oraz są ze sobą w różny sposób powiązane. Zazwyczaj nie można całkowicie oddzielić zarządzania jednym z rodzajów ryzyka od pozostałych

Rys. 2. Schemat metody badania efektywności systemu zarządzania ryzykiem metodą Data Envelopment Analysis (DEA)

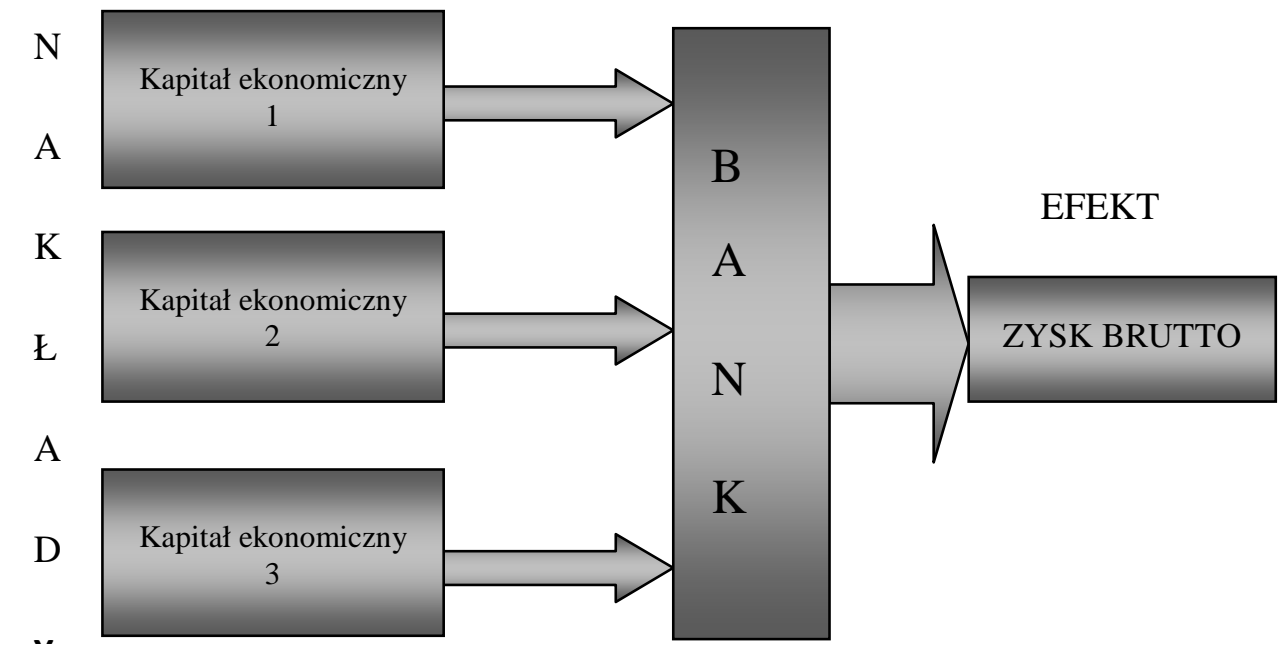

Źródło: opracowanie własne.

Do implementacji obydwu modeli DEA wykorzystano program udostępniony w serwisie DEA online ${ }^{8}$ służący do optymalizacji liniowej. Badaniami objęto banki notowane na Giełdzie Papierów Wartościowych w Warszawie. Oceny efektywności dokonano, wykorzystując dane finansowe banków za lata 2012-2013. Kapitał ekonomiczny na pokrycie ryzyka z danego typu działalności obliczono, wykorzystując model Value at Risk przy 99-procentowym poziomie ufności, opierając się na zmienności kwartalnych wyników finansowych ${ }^{9}$. Aby obliczyć kapitał ekonomiczny na pokrycie ryzyka w określonym roku, policzono kwartalną zmienność określonej kategorii wyniku finansowego (mierzoną odchyleniem standardowym) $\mathrm{z}$ danego roku. Następnie tak policzoną zmienność przekształcono na zmienność dla okresu rocznego. Kapitał ekonomiczny można obliczyć, wykorzystując następujący wzór:

$$
\mathrm{K}=\mathrm{m} \times \text { or }
$$

gdzie:

$\mathrm{K}$ - kapitał ekonomiczny;

\footnotetext{
${ }^{8} \mathrm{https}: / / \mathrm{www} \cdot$ deaos.com.

${ }^{9}$ Sposób obliczania kapitału ekonomicznego na pokrycie ryzyka opisany jest między innymi w: J. Besis, Risk management in banking, John Wiley \& Sons, New York 1998.
} 
m - stała, której wysokość zależy od przyjętego przedziału ufności (dla 99\% wynosi $2,33)$

or - zmienność dla okresu rocznego.

Wartości wyliczonego w ten sposób kapitału ekonomicznego dla badanych banków znajdują się w tabeli 1.

Tabela 1. Kapitały ekonomiczne na pokrycie ryzyka dla badanych banków w latach 20122013

\begin{tabular}{|l|c|c|c|c|c|c|}
\hline & \multicolumn{3}{|c|}{$\mathbf{2 0 1 2}$} & \multicolumn{3}{c|}{$\mathbf{2 0 1 3}$} \\
\hline & $\mathbf{k 1}$ & $\mathbf{k 2}$ & $\mathbf{k 3}$ & $\mathbf{k 1}$ & $\mathbf{k 2}$ & $\mathbf{k 3}$ \\
\hline Alior Bank S.A. & 59413 & 27112 & 89361 & 197934 & 11792 & $\begin{array}{c}17 \\
049\end{array}$ \\
\hline PKO BP S.A. & $\begin{array}{c}1048 \\
336\end{array}$ & 207536 & 376657 & 668946 & 80369 & $\begin{array}{c}15 \\
530\end{array}$ \\
\hline Millenium S.A. & 10858 & 81340 & 28511 & 102630 & 59124 & 8600 \\
\hline BOŚ S.A. & 2579 & 22649 & 12459 & 24860 & 13389 & 1816 \\
\hline BZ WBK S.A. & 15795 & 272418 & 68563 & 251330 & 205488 & 7111 \\
\hline Getin Bank S.A. & 16494 & 5222 & 32424 & 694536 & 19244 & $\begin{array}{c}33 \\
492\end{array}$ \\
\hline ING Bank Śląski S.A. & 8614 & 43209 & 20339 & $\begin{array}{c}1305 \\
435\end{array}$ & 290693 & 7579 \\
\hline Bank Pekao S.A. & 35994 & 244326 & 82510 & 150815 & 266805 & $\begin{array}{c}64 \\
990\end{array}$ \\
\hline
\end{tabular}

Źródło: opracowanie własne na podstawie sprawozdań finansowych banków.

Zyski brutto banków w latach 2012-2013 traktowane w modelu jako efekty funkcjonowania systemu zarządzania ryzykiem zamieszczono w tabeli 2.

Tabela 2. Zyski brutto banków objętych badanie w latach 2012-2013

\begin{tabular}{|l|c|c|}
\hline & $\mathbf{2 0 1 2}$ & $\mathbf{2 0 1 3}$ \\
\hline Alior Bank S.A. & 229755 & 341235 \\
\hline PKO BP S.A & 4645261 & 4044506 \\
\hline Millenium S.A. & 556871 & 672040 \\
\hline BOŚ S.A. & 42438 & 75728 \\
\hline BZ WBK S.A. & 1837039 & 2514717 \\
\hline Getin Bank S.A. & 820335 & 330887 \\
\hline ING Bank Śląski S.A. & 1016100 & 1192900 \\
\hline Bank Pekao S.A. & 3664334 & 3454230 \\
\hline
\end{tabular}

Źródło: sprawozdania finansowe banków.

Wartości współczynników efektywności dla badanej grupy banków przedstawiono w tabeli 3. W roku 2012 dwa banki uzyskały maksymalny 100-procentowy poziom efektywności. Są to: Getin Bank S.A. oraz ING Bank Śląski S.A. Dwa banki o najniższych współczynnikach efektywności to: Bank Ochrony Środowiska S.A $(13,9 \%)$ oraz Alior Bank S.A (9,5\%). W roku 2013 trzem bankom udało się uzyskać maksymalny poziom efektywności: PKO BP S.A., BZ WBK S.A. oraz Bank Pekao S.A. W grupie banków o najniższym poziomie efektywności ponownie znalazł się Bank Ochrony Środowiska $(32,7 \%)$. 
Przeciętny współczynnik efektywności w bankach notowanych na Giełdzie Papierów Wartościowych w Warszawie w roku 2012 wyniósł 61,9\%, w kolejnym roku średni współczynnik efektywności był wyższy i wynosił $67 \%$. Może to świadczyć o poprawie ogólnej efektywności zarządzania ryzykiem w badanej grupie banków.

W tabeli 4 zamieszczono klasyfikację banków według średniego współczynnika efektywności za lata 2012-2013. Najbardziej efektywnym system zarządzania ryzykiem charakteryzuje się bank BZ WBK ze średnim współczynnikiem na poziomie 99,3\%.

Tabela 3. Współczynniki efektywności systemów zarządzania ryzykiem w badanej grupie banków w latach 2012-2013 (\%)

\begin{tabular}{|l|c|c|c|}
\hline & $\begin{array}{c}\text { Efektywność } \\
\mathbf{2 0 1 2}\end{array}$ & $\begin{array}{c}\text { Efektywność } \\
\mathbf{2 0 1 3}\end{array}$ & $\begin{array}{c}\text { Średnia } \\
\mathbf{2 0 1 2 - 2 0 1 3}\end{array}$ \\
\hline Alior Bank S.A. & 9,5 & 57,5 & 33,5 \\
\hline PKO BP S.A. & 40,8 & 100,0 & 70,4 \\
\hline Millenium S.A. & 43,5 & 67,4 & 55,4 \\
\hline BOŚ S.A. & 13,9 & 32,7 & 23,3 \\
\hline BZ WBK S.A. & 98,6 & 100,0 & 99,3 \\
\hline Getin Bank S.A. & 100,0 & 34,2 & 67,1 \\
\hline ING Bank Śląski & 100,0 & 44,5 & 72,3 \\
S.A. & 88,9 & 100,0 & 94,4 \\
\hline Bank Pekao S.A. & \multicolumn{3}{|l}{} \\
\hline
\end{tabular}

Zródło: opracowanie własne

Najmniejszą efektywność w badanym okresie uzyskał system zarządzania ryzykiem w Banku Ochrony Środowiska S.A. Współczynnik efektywności dla tego systemu wynosi $23,3 \%$.

Tabela 4. Klasyfikacja banków na podstawie średniego współczynnika efektywności ich systemów zarządzania ryzykiem

\begin{tabular}{|c|l|c|}
\hline Lp. & \multicolumn{1}{|c|}{ Nazwa banku } & $\begin{array}{c}\text { Średni współczynnik efektywności } \\
\text { systemu zarządzania ryzykiem } \\
\text { w latach 2012-2013 }(\boldsymbol{\%})\end{array}$ \\
\hline 1 & BZ WBK S.A. & 99,3 \\
\hline 2 & Bank Pekao S.A. & 94,4 \\
\hline 3 & ING Bank Śląski S.A. & 72,3 \\
\hline 4 & PKO BP S.A. & 70,4 \\
\hline 5 & Getin Bank S.A. & 67,1 \\
\hline 6 & Millenium S.A. & 55,4 \\
\hline 7 & Alior Bank S.A. & 33,5 \\
\hline 8 & BOŚ S.A. & 23,3 \\
\hline
\end{tabular}

Źródło: opracowanie własne. 


\section{PODSUMOWANIE}

Analiza efektywności funkcjonowania systemu zarządzania ryzykiem jest niezwykle ważnym elementem oceny działalności banku komercyjnego. W artykule zaprezentowano możliwości zastosowania metody DEA do analizy efektywności systemów zarządzania ryzykiem finansowym w bankach. Wykorzystanie tej metody pozwala na ocenę efektywności bez znajomości zależności funkcyjnej pomiędzy ryzykiem a wynikami finansowymi osiągniętymi przez bank. Metoda DEA umożliwia dokonanie względnej oceny funkcjonowania systemu zarządzania ryzykiem w relacji do podmiotów konkurencyjnych.

\section{LITERATURA}

[1] Besis J., Risk management in banking, John Wiley \& Sons, New York 1998.

[2] Charnes A., Cooper W.W.,. Lewin A.Y, Seiford L.M., Data Envelopment Analysis: Theory, Methodology and Aplications, Kluwer Academic Publishers, Dordrecht 1995.

[3] Charnes A., Cooper W., Rhodes E., Measuring the efficiency of decisionmaking units, European Journal of Operational Research 1978 vol. 2.

[4] https://www.deaos.com.

[5] Kudła J., Struktury organizacyjne banków komercyjnych, Twigger, Warszawa 2001.

[6] Rogowski G., Metody analizy i oceny działalności banku na potrzeby zarzadzania strategicznego, Wydawnictwo Wyższej Szkoły Bankowej w Poznaniu, Poznań 1998.

\section{THE USE OF DEA METHOD FOR AN ANALYSIS OF EFFECTIVENESS OF RISK MANAGEMENT IN SELECTED BANKS}

The problem of assessing and measuring the effectiveness is frequently discussed in the economic literature. In the economic sense efficiency is the relationship between the obtained outputs and inputs needed to achieve them. The higher the ratio the more efficient is the system. Thus the more efficient systems require less input to achieve the certain effect or the system can achieve greater outputs from a certain level of inputs. The effectiveness of management of financial risk in the bank can be measured by examining the relationship between bank profitability and risks associated with its activities. The article presents the method for evaluation of the effectiveness of risk management in the bank using Data Envelopment Analysis (DEA). To make such assessment possible, inputs and outputs of risk management system should be defined. It was assumed that the effect of the system is profit achieved by the bank. Through the risk management system, which is integrated into the whole process of managing the assets and liabilities of the bank, bank can control the amount of risk taken. The efficiency of the system will be expressed by achieving a given result with the least level of risk. In the paper authors analyzed the relationship between financial results and risk taken by banks which are listed in the Warsaw Stock Exchange.

Keywords: risk management, efficiency, DEA method.

DOI:10.7862/rz.2014.hss.17

Przesłano do redakcji: kwiecień 2014

Przyjęto do druku: lipiec 2014 